\title{
Editorial: Research methodology in library and information studies (LIS)
}

Judith Broady-Preston

\section{Introduction}

In 2012 LIR published a special issue of the journal devoted to papers which analysed contemporary research methodologies, models and methods of relevance to the information profession and the LIS discipline (Broady-Preston, 2012). This issue was well received by researchers and practitioners alike.

As a result, the editorial board decided to revisit the idea at a similar point in the UK Research Excellence Framework (REF) cycle, and a general call for papers was distributed globally to numerous lists in 2017. The papers resulting from this 2017 call are published in two issues of the journal in 2017-2018, of which this is the first. All papers are unique to the journal and have been through rigorous double blind peer review prior to acceptance. Thanks are due to all those colleagues who completed reviews.

The papers in 2017-2018 originate from research teams working in Australia, Canada, New Zealand, Thailand and the USA as well as the UK, regardless of the timing of the call to coincide with that of the research evaluation system in the UK. A wide range of topics are addressed; as in 2012, there is a mix ranging from work by authors with an established global reputation and others derived from doctoral theses successfully defended in the last two years.

\section{Papers}

The six papers published here examine a wide range of qualitative research methods. The first is co-authored by two highly experienced researchers with an extensive publication record and with specific expertise in Grounded Theory and Action Research. Unusually for papers in this and other academic disciplines, the content is presented as a critical conversation between the two authors, AbbottHalpin and Bryant, reviewing issues in relation to their core areas of expertise Grounded Theory and Action Research. The stated purpose of the paper is to

\section{Author}

Professor Judith Broady-Preston is Director of the Institute of Professional Development at Aberystwyth University, and has been a member of the Editorial Board of Library and Information Research since 2002.

Email: jbp@aber.ac.uk 
enable researchers planning investigative studies to navigate a successful path through the rich body of contemporary resources and methods available, in addition to contributing to our understanding of certain key aspects of undertaking research in the field. Their discussion of Grounded Theory Method [GTM] is of enormous benefit to those researchers grappling to understand not only the differing philosophical viewpoints underpinning GTM in its several forms, but also of practical use in determining whether or not a form of GTM is a sensible approach for their particular area of interest. Coincidentally, the paper will also be a useful addition to the standard reading list for those such as I who teach GTM.

The Abbott-Halpin and Bryant review is followed by Cossham's evaluation of phenomenography as a research method. Based on the outcomes of a research project completed in 2017, the author identifies three issues in using this approach which seemingly have not been highlighted previously, also offering a clear delineation of the differences between phenomenography and phenomenology which are similar but not synonymous, and equally, often confused or conflated. Her conclusion is that phenomenography offers "a valuable perspective on and understanding of users and their experience", offering opportunities to improve customer services across a variety of organisations.

Remaining with interpretive methods, Everhart and Johnston evaluate the potential of meta-ethnography in relation to theory building and generation in LIS, offering specific examples of both actual and potential applications in the field. Outlined in the paper is a critical description of the classic seven step process for conducting a meta-ethnography, identified in 1988 by Noblit and Hare. Their contention is that one of the key benefits of the method is that it allows for and requires a variety of perspectives: a factor of central importance in a multidisciplinary field such as LIS.

The Canadian team of Dalmer, Stooke, and McKenzie introduce, identify and review the central tenets of Institutional Ethnography (IE), demonstrating its relevance to achieving a critical understanding of LIS practice and scholarship. Originally developed in the late twentieth century by the Canadian sociologist, Dorothy Smith, Dalmer et al. outline how IE may be used as both a systematic mode of inquiry and an informal strategy for examining everyday practice in LIS. With its emphasis on examining and understanding the 'small stuff' of the everyday information experience, Dalmer et al. conclude that IE "can contribute to a better understanding of the nuances of library researchers', practitioners' and patrons' everyday practices".

In the fifth paper of the issue, Tucker explores how a variety of methodologies can be used to explore threshold concepts in LIS. As well as providing helpful overviews of both threshold concepts and competency theory, the paper presents a case illustration of how the author employed grounded theory in her own research into the learning experiences of professional searchers and graduate students. The article concludes that grounded theory offers particular benefits for investigating and discovering threshold concepts.

The final paper is by Bedi and Webb, who provide a thoughtful and in-depth discussion of a method that to date has not been widely employed by LIS 
researchers: photo-elicitation. As well as providing rich philosophical and theoretical context for the method, the authors draw on their own experiences to argue that it represents a productive and collaborative means of investigating the "lived experiences" of library users.

\section{Conclusion}

This is the second volume of LIR addressing purely methodological issues in LIS research and the response to the call for papers has been on a scale similar to that of the first volume. In 2012 I concluded that this "clearly demonstrate[d]an interest and engagement in the concept and process of research which bodes well for the future of the discipline and the profession" (Broady-Preston, 2012), a view reinforced by Abbott-Halpin and Bryant in their paper in this new volume. They conclude their discussion:

There is a strong and ever-developing awareness of the importance of research; not only in terms of understanding the ways in which the internet age has dramatically changed the research process itself and the role if LIS professionals in providing support to researchers, but also the extent to which this body of professionals themselves undertake their own research and use the findings of their colleagues and others.

\section{References}

Broady-Preston, J. (2012). Research methodology in library and information studies (LIS). Library and Information Research, 36(112), 1-5.

\section{Acknowledgement}

I would like to extend my thanks to the editorial team of Library and Information Research who once again have shown exemplary patience in supporting a guest editor, especially Diane Pennington and Simon Wakeling without whom these issues would probably not have been finalised. My thanks to you both.

\section{Open access and copyright}

Library and Information Research is an open access journal. A freely available copy of this paper may be downloaded from the journal's website: http://www.cilipjournals.org.uk/

Copyright and associated moral rights in works published in Library and Information Research are retained by the author(s) but this paper may be used freely, with proper attribution, in educational and other non-commercial settings. 